\title{
Sugarcane transcriptome. A landmark in plant genomics in the tropics
}

\author{
Paulo Arruda
}

In the last 10 years, when a vast array of genomic tools became available, new opportunities have been opened to explore complex plant biological systems. This is the case of sugarcane, an important cash crop of the tropics that is cultivated for its stalks, which accumulate sucrose. It contributes with $60 \%$ of the raw sugar production and in some countries, like Brazil, part of its biomass is also used for the production of ethanol. Sugarcane became an important crop when geneticists crossed Saccharum officinarum, a high-sugar species, to Saccharum spontaneum, a wild and vigorous relative (Berding and Roach, 1987) 1). Progress in sugarcane genetics, however, has been slow because of its genomic complexity, characterized by a high level of ploidy (Sreenivasan, et al., 1987). The modern sugarcane hybrids present $2 \mathrm{n}=100$ to 130 chromosomes derived from a combination of $S$. officinarum $(2 \mathrm{n}=80$ chromosomes) and $S$. spontaneum ( $2 \mathrm{n}=40$ to 128 chromosomes) (Butterfield et al., 2001; D'Hont and Glaszmann, 2001). Because of the different basic chromosome sets of $S$. officinarum and $S$. spontaneum, the hybrid genome presents complex chromosome organization and recombinational events (Grivet et al.,1996; Ming et al., 1998). However, despite the high level of ploidy, the monoploid genome sizes of $S$. officinarum and S. spontaneum are around 930 and $750 \mathrm{Mbp}$, respectively (D'Hont and Glaszmann, 2001), a value comparable to that of sorghum ( $\sim 760 \mathrm{Mbp})$ and about twice that of rice ( $\sim 430 \mathrm{Mbp}$ ).

The understanding of the complex genome of sugarcane will benefit from a number of discoveries on other cereals, including the high chromosome synteny between grasses (Freeling, 2001), the availability of high density maps for sorghum and maize and the completion of genome sequence of rice. However, additional genomic resources will be necessary to reach this goal, some of which are now beginning to become available. For example, a sugarcane Bacterial Artificial Chromosome (BAC) library of more than 100,000 clones has been constructed (Tomkins et al., 1999) and will be of tremendous value for the construction of a physical map and to extend the comparison with other grasses. Recently several projects aiming at sequencing sugarcane Expressed Sequence Tags (ESTs) have been initiated in South Africa (Carson and Botha, 2000) and Australia (Casu et al., 2001). But perhaps one of the most significant contributions, not only for sugarcane but also for grass genomics, is now being presented in this special issue of Genetics and Molecular Biology. The publication of this special issue is one of the results of the Sugarcane EST Project (SUCEST) (http://sucest.lad.ic.unicamp.br/en) carried out by the Brazilian ONSA consortium (Simpson and Perez, 1998). SUCEST has built a database containing 238,000 ESTs from 26 cDNA libraries constructed from several organs and tissues sampled at different developmental stages. Around 200 researchers from several Universities and Research Institutes from the State of São Paulo and other places around the country contributed to build up the SUCEST database. Bioinformatic tools were developed that allowed the assembling and sequence analysis of the sugarcane ESTs. Forty-nine groups headed by researchers with diverse expertise in many different areas of biological science contributed for a detailed annotation of the SUCEST database. The first 3 research articles of this special issue are devoted to describing the cDNA library construction and bioinformatics of the SUCEST project. The remaining 34 research articles comprise the analysis of sugarcane ESTs related to signal transduction, plant development, biotic and abiotic stress, gene regulation, transposable elements, polymorphism analysis, organelle constitution and a miscellaneous of topics related to plant metabolism.

I believe that this collection of articles will be a highly valuable resource for the plant biology community to extend investigation on sugarcane and related grasses such as maize, sorghum and rice.

\section{REFERENCES}

Berding, N. and Roach, B.T. (1987). Germplasm collection, maintenance, and use. In: Sugarcane Improvement Through Breeding (Heinz D.J., ed.), Elsevier, Amsterdam, pp. 143-210.

Butterfield, M.K., D'Hont, A. and Berding, N. (2001). The sugarcane genome: A synthesis of current understanding, and lessons for breeding and biotechnology. Proc. S. Afr. Sug. Technol. Ass. 75: 1-5.

Carson, D.L. and Botha, F.C. (2000). Preliminary analysis of expressed sequence tags for sugarcane. Crop Sci, 40: 1769-1779.

Casu, R., Dimmock, C., Thomas, M., Bower, N., Knight, D., Grof, C., Mcintyre, L., Jackson, P., Jordan, D., Whan, V., Drenth, J., Tao, Y. and Manners, J. (2001). Genetic and expression profiling in sugarcane. Proc. Int. Soc. Sugarcane. Technol. 24: 626-627 
D'Hont, A. and Glaszmann, J.C. (2001). Sugarcane genome analysis with molecular markers, a first decade of research. Proc. Int. Soc. Sugarcane. Technol. 24: 556-559.

Freeling, M. (2001). Grasses as a single genetic system. Reassessment 2001. Plant Physiol. 125: 1191-1197.

Grivet, L., Dhont, A., Roques, D., Feldmann, P., Lanaud, C. and Glaszmann, J.C. (1996). RFLP mapping in cultivated sugarcane (Saccharum spp): Genome organization in a highly polyploid and aneuploid interspecific hybrid. Genetics 142: 987-1000.

Ming, R., Liu, S.C., Lin, Y.R., da Silva, J., Wilson, W., Braga, D., van Deynze, A., Wenslaff, T.F., Wu, K.K., Moore, P.H., Burnquist, W., Sorrells, M.E., Irvine, J.E. and Pat- erson, A.H. (1998). Detailed alignment of Saccharum and Sorghum chromosomes: comparative organization of closely related diploid and polyploid genomes. Genetics 150 : 1663-1682.

Simpson, A.J.G. and Perez, J.F. (1998). Latin America - ONSA, the São Paulo virtual genomics institute. Nat. Biotechnol., 16: 795-796.

Sreenivasan, T.V., Ahloowalia, B.S. and Heinz, D.J. (1987). Cytogenetics. In: Sugarcane Improvement Through Breeding (Heinz D. J., ed.), Elsevier, Amsterdam, pp. 211-253

Tomkins, J.P., Yu, Y., Miller-Smith, H., Frisch, D.A., Woo, S.S. and Wing, R.A (1999). A bacterial artificial chromosome library for sugarcane. Theor. Appl. Genet. 99: 419-424. 